\title{
The Use of Filtration Techniques for the Lysis and Study of Red Blood Cells
}

\author{
Donald E. Hultquist*, Michael R. Vasko*, and Robert H. Gray $\dagger$ \\ Departments of "Biological Chemistry and † Environmental and Industrial Health. The \\ University of Michigan, Ann Arbor
}

\begin{abstract}
A filtration technique for the gentle lysis of erythrocytes has been developed using cellulose triacetate membranes. When cell suspensions are filtered under nitrogen pressure, lysis occurs at the surface of the filter in such a way that the cell ghosts are retained on the filter. The contents of the cell are extruded through the pores of the filter without mixing with the cell suspension. Cell ghosts and intact erythrocytes have been collected on membranes and examined by electron microscopy. These preparations have the advantage of being free of the structural artifacts that result from centrifugation. In addition, the filter facilitates preparation for electron microscopy by providing a support for the sample during fixation and then dissolving during the dehydration of the sample.
\end{abstract}

Key words: erythracytes, filtration, hemolysis, cell membrane, electron microscopy

\section{INTRODUCTION}

The development of techniques for the isolation and lysis of erythroid cells has been central to the progress that has been made in understanding their biochemistry and morphology. However, there are limitations to the use of these techniques in characterizing the membranous fractions of erythroid cells. Centrifugation of red cells causes a number of artifacts, including collapse of the cell shape and the sedimentation of particles within the cell $(1,2)$. Freeze-thaw, hypotonic shock, and other hemolytic procedures disrupt the normal state of membranes. Moreover, these procedures allow for artifactual redistribution of cellular components between cytoplasmic and membranous fractions.

Filtration methods have long been used to remove cells, microorganisms, and subcellular particles (3) from suspension and to separate these particles on the basis of size. Erythrocytes have been filtered on polycarbonate, cellulose, cellulose ester, and plastic filters, and the ability to pass through pores smaller than the dimensions of the cell has been used as a measure of deformability of normal and abnormal red blood cells (4-9). This paper describes the use of filtration for the gentle lysis of human and chicken erythrocytes and the preparation of the resulting cell membranes for electron microscopy.

Received January 4, 1977; accepted June 29, 1977

Address reprint requests to Donald E. Hultquist, Ph.D., Department of Biological Chemistry, Medical Science Bldg. I, The University of Michigan, Ann Arbor, MI 48109. 


\section{MATERIALS AND METHODS}

\section{Red Blood Celis}

Freshly drawn human blood was stored for a maximum of 2 hours in the presence of heparin at $4^{\circ} \mathrm{C}$ before use. Human outdated cells, graciously donated by St. Joseph Mercy Hospital Blood Bank, Ann Arbor, Michigan, were stored at $4^{\circ} \mathrm{C}$ in acid-citratedextrose Formula A ( $1.66 \mathrm{~g}$ of glucose, $1.49 \mathrm{~g}$ of trisodium citrate, $0.54 \mathrm{~g}$ of citric acid, and $67.5 \mathrm{ml}$ of water per $450 \mathrm{ml}$ of blood) and were used within 2 weeks of the expiration date. Washed chicken red cells, purchased from Pel-Freeze Company, were stored at $4^{\circ} \mathrm{C}$ in the presence of heparin. Immediately before lysis, the cells were washed 3 times with $0.9 \% \mathrm{NaCl}$ to remove white blood cells and other contaminants. The red blood cells, suspended in the $\mathrm{NaCl}$ solution, were collected by centrifugation at $5,000 \mathrm{~g}$ for 10 minutes. After each spin, the supernatant fraction and the buffy coat, together with some red blood cells, were decanted. The thoroughly washed cells were finally suspended in $0.25 \mathrm{M}$ sucrose.

\section{Filtration Procedure for the Lysis of Red Cells}

Filtration was performed at $4^{\circ} \mathrm{C}$ under nitrogen pressure in an Amicon Model 52 Diaflo cell with GA-type Triacetate Metricel membranes from Gelman Instrument Company. The GA-1, GA-3, and GA-8 filters used in these experiments were specified by the manufacturer as having mean-flow pore sizes (mps) of 5.0,1.2, and $0.2 \mu$, respectively. Immediately before each experiment, $0.25 \mathrm{M}$ sucrose was forced through the filter. Washed cells, suspended in $0.25 \mathrm{M}$ sucrose, were filtered under a pressure of less than 40 psi. The filtrate was collected in 1-3 ml fractions. The degree of lysis was determined by reading the absorbance of hemoglobin at $416 \mathrm{~m} \mu$. When the desired volume of solution had passed through the filter, pressure was released and the suspension that had not passed the filter was carefully decanted. The material on the filter pad was directly fixed and stained for electron microscopic analysis.

\section{Electron Microscopy}

Filters with adhering cells and cell ghosts were prepared for electron microscopy by fixation in $3 \%$ glutaraldehyde (Ladd Research Industries) containing $0.1 \mathrm{M}$ phosphate buffer, $\mathrm{pH} 7.3$, for 2 hours. The samples were washed 3 times in $0.2 \mathrm{M}$ sucrose $/ 0.1 \mathrm{M}$ phosphate buffer ( $\mathrm{pH} 7.3$ ), postfixed in $2 \%$ osmium tetroxide/0.1 M phosphate buffer for 2 hours, rinsed twice in phosphate buffer, and finally washed in water. The filter was cut into small pieces about $0.5-1 \mathrm{~mm}$ square. The filter pieces we re dehydrated by several washes with $50,70,95$, and $100 \%$ ethanol, followed by two 30 minute washes in propylene oxide, which solubilized the filter. The samples were placed in a $1: 1$ mixture of propylene oxide-Epon (Shell Oil Co.) for 1-4 hours and then in Epon overnight. Samples were then embedded in freshly prepared Epon and polymerized for 48 hours at $60^{\circ} \mathrm{C}$.

Sections were prepared with a diamond knife on a Reichert Om-U2 ultramicrotome and sections were placed on Formvar-carbon-coated copper grids. Mounted sections were poststained with aqueous $7 \%$ uranyl magnesium acetate (10) and lead citrate (11). Electron microscopic examinations were made with an ARI EM-6B electron microscope. 


\section{RESULTS}

Some of the characteristics of the filtration technique for the lysis of erythrocytes are shown in Figures 1 and 2. In each of these experiments the $416 \mathrm{~m} \mu$ absorbance of hemoglobin in the supernatant fractions was used as a measure of the degree of lysis. Figure 1 shows the manner in which the degree of lysis changes as the filtration proceeds. No cells or stroma passed through the GA-1 ( $5 \mu \mathrm{mps})$ filter as judged by the failure of centrifugation of the filtrate to sediment cells or stroma or to decrease absorbance. In contrast, the red cell suspension above the filter showed no free hemoglobin in solution when the procedure was interrupted and the suspension centrifuged. If this suspension of red cells (which had failed to lyse) was filtered on a new GA-1 membrane, lysis occurred similarly to that described in Figure 1. However, when a filter that had previously been used with a large number of cells was then employed with a fresh suspension of cells, no additional lysis was observed. Red cell membranes could be removed from the filter by inverting it and then passing solution under pressure through the filter in the opposite direction.

The degree of lysis was dependent on filter pore size, the nature of the suspending medium, and cell concentration. Lysis occurred on GA-type membrane filters of mean pore sizes ranging from $5 \mu$ to $0.2 \mu$. The filters with larger pores accomplished a greater degree of lysis and showed a faster flow rate. The degree of lysis in sucrose solution was greater than that in isotonic saline. Figure 2 shows the relationship between amount of erythrocytes placed on a GA-1 $(5 \mu$ mps) membrane (in a standard volume) and lysis that occurred when the filtration was brought to completion. Figure 2 a shows that with small amounts of erythrocytes there is a linear relationship between total amount of lysis and number of cells filtered, but with an increasing number of cells a state is reached
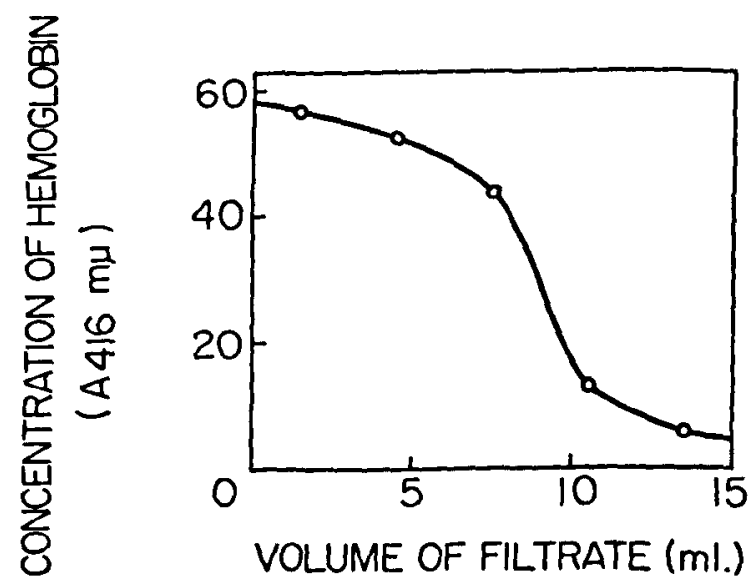

Fig. 1. Changes in the degree of lysis during the progression of the filtration of ery throcytes. Washed outdated human erythrocy tes $(1 \mathrm{ml})$, suspended in $29 \mathrm{ml}$ of $0.25 \mathrm{M}$ sucrose, were filtered at a pressure of 40 psi on a GA-1 ( $5 \mu \mathrm{mps}$ ) filter as described in Materials and Methods. The filtrate was analyzed for hemoglobin by reading absorbance at $416 \mathrm{m \mu}$. 

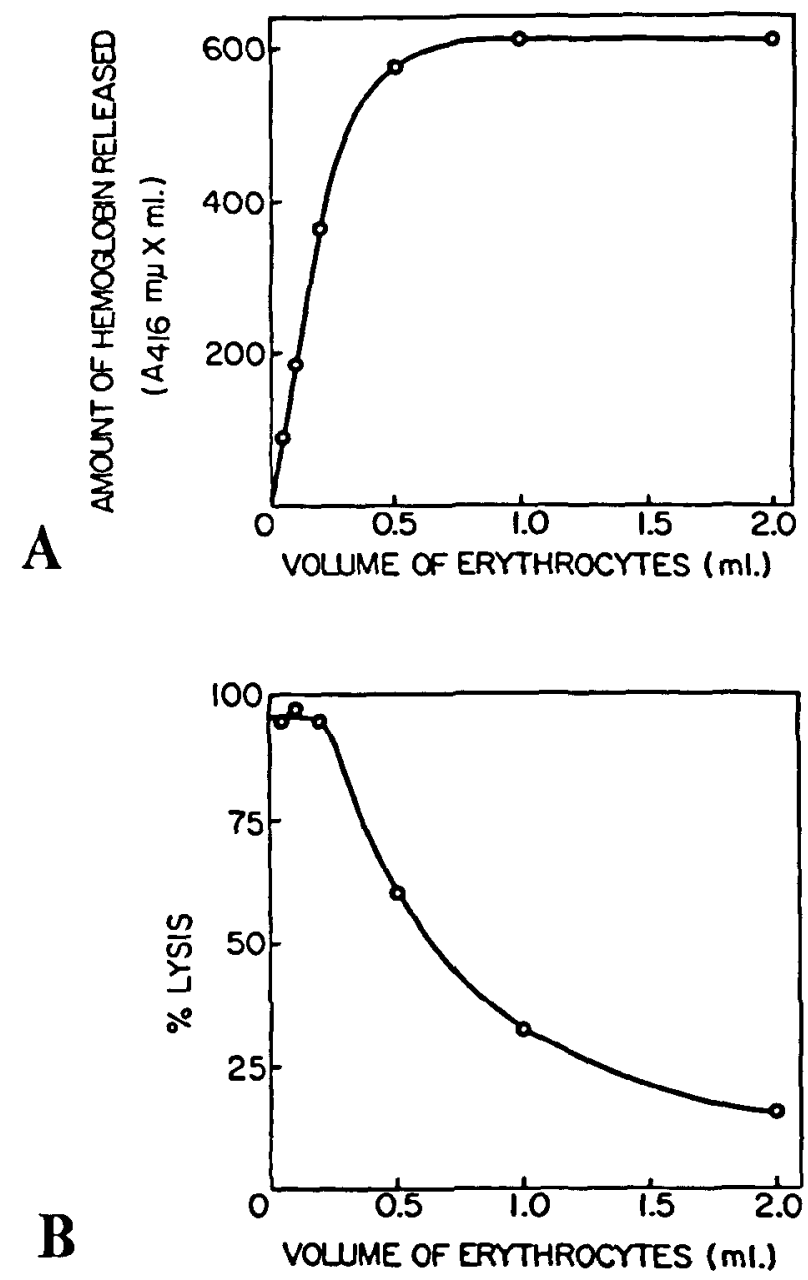

Fig. 2. Variation in the amount of lysis with changes in the number of erythrocytes placed on a GA-1 (5 $\mu \mathrm{mps}$ ) filter. Varying volumes of washed, fresh erythrocytes were suspended in $20 \mathrm{ml}$ of $0.25 \mathrm{M}$ sucrose and filtered to dryness at a pressure of 40 psi on a GA-1 membrane as described in Materials and Methods. Amount of hemoglobin in each total filtrate is expressed as total absorbance at $416 \mathrm{m \mu}$ (A $416 \mathrm{m \mu} X$ volume in $\mathrm{ml}$ ) and is used as a measure of lysis. A) Total amount of lysis as a function of the amount of cells placed on the membrane. B) Percentage lysis as a function of the amount of cells placed on the membrane. Total lysis is based on the amount of absorbance at $416 \mathrm{~m} \mu$ present in the supernatant fraction resulting from hemoly sis by hypotonic shocking.

where no further lysis occurs. Figure $2 \mathrm{~b}$ shows that the procedure achieves nearly complete lysis when smaller amounts of cells are applied to the filter.

The mechanism by which filtration results in lysis of red cells is illustrated in Figure 3. This figure shows an electron micrograph of a fraction collected on a GA-8 $(0.2 \mu \mathrm{mps})$ membrane following filtration lysis of nucleated red blood cells from chickens. The cell membranes and the entrapped nuclei are seen lined up on the surface of the filter (see arrow) before it was solubilized during the dehydration procedure. This figure illustrates that the chicken erythrocyte cell membranes have been pressed down into the small pores of the filter. Some of the nuclei are being disrupted in a similar manner, by having their membranes forced into the filter's pores. 


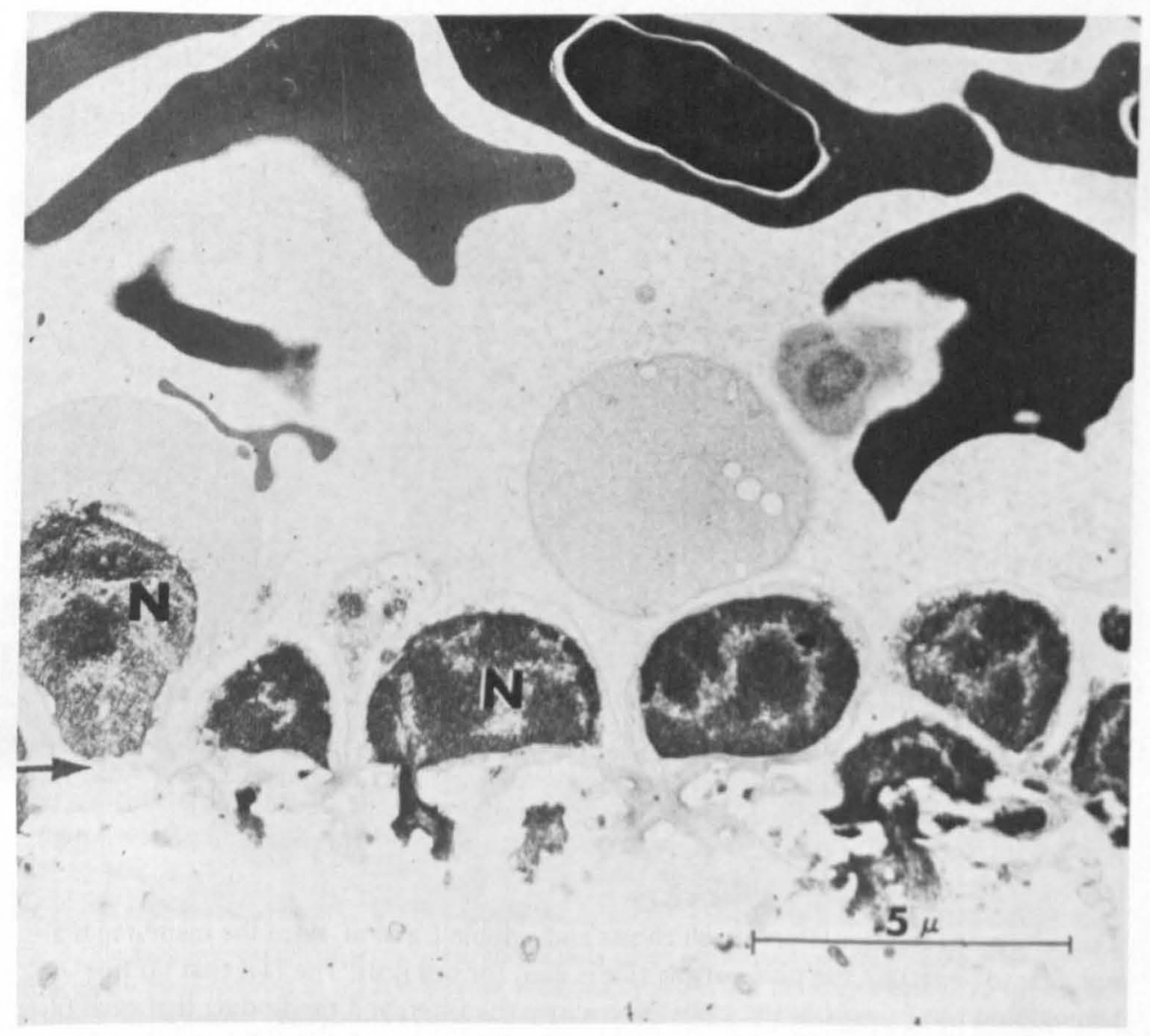

Fig. 3. Electron micrographs of ghosts of chicken nucleated red cells collected on a GA-8 $(0.2 \mu \mathrm{mps})$ filter during filtration lysis. A suspension of $1 \mathrm{ml}$ of washed cells in $24 \mathrm{ml}$ of $0.25 \mathrm{M}$ sucrose was filtered at 40 psi until $2 \mathrm{ml}$ had passed through the membrane. The filter mat was prepared for electron microscopic observation as described in Materials and Methods. Arrow indicates the probable position occupied by the upper surface of the filter membrane before it was solubilized (final magnification, $\times 7,200$ ).

Figure 4 shows an example of outdated human erythrocytes filtered under pressure on a GA- $8(0.2 \mu \mathrm{mps})$ membrane. The cell ghosts and partially lysed cells are collected above the position that was occupied by the membrane. The cell ghosts not in direct contact with the filter show a wider range of electron opacity due to their variable hemo. globin content. For the sake of comparison, Figure 5 shows an electron micrograph of stromata collected by centrifugation following the lysis of outdated human blood cells in a Dounce homogenizer.

\section{DISCUSSION}

Filtration on Gelman filters composed of cellulose derivatives is a simple, rapid, and gentle procedure for the lysis of red blood cells. If relatively small amounts of cells are employed, the lysis is essentially complete (Fig. 2b). Moreover, the filtration accomplishes 


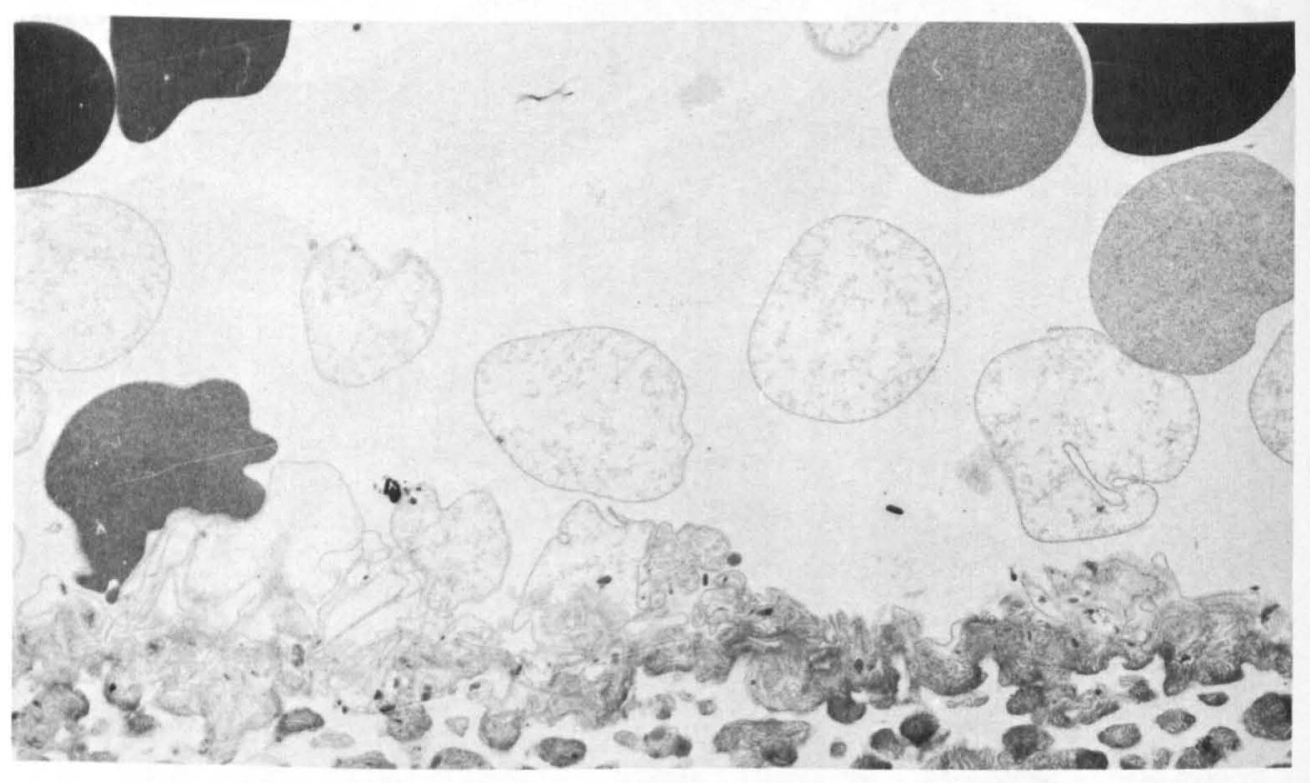

Fig. 4. Electron micrographs of ery throcyte ghosts collected on a GA-8 $(0.2 \mu$ mps) membrane during a filtration lysis of outdated human red blood cells. A suspension of $1 \mathrm{ml}$ of red cells in $24 \mathrm{ml}$ of 0.25 M sucrose was filtered until approximately $7 \mathrm{ml}$ had passed through the membrane. The filter pad was prepared for electron microscopic observation as described in the text (final magnification, $\times 4,400$ ).

a simultaneous fractionation of cell ghosts and soluble fraction, since the membranes are not able to penetrate the pores of the filters used for cell lysis. The fact that no free hemoglobin was present in the suspension above the filter, and the finding that each filter was capable of lysing only a certain number of cells, suggested that cell lysis was taking place at the surface of the filter. It has been demonstrated by electron microscopy that membranes of the red cells are lysed within the pores of the filter, and this explains why the hemoglobin is extruded through the membrane without mixing with the suspension above the filter.

This simultaneous lysis and separation of soluble and particulate fractions should be of great value in attempting to evaluate whether cell components are cytoplasmic or membranous. Hemoglobin, enzymes, metal ions, and a vast number of other molecules are found associated with the erythrocyte membrane following lysis by other procedures. However, it has not been possible to establish whether the composition of such membrane preparations is similar to that of the intact red cell membrane or if artifactual binding and/or dissociation of components has resulted as a consequence of alteration of the membrane. Certainly the time span between hemolysis and separation of soluble and membranous fractions that is inherent with other techniques gives the outer surface of the membrane every opportunity to interact with soluble cellular components. By minimizing membrane damage and avoiding contact between soluble cellular components and the outer surface of the membrane, this filtration technique should provide membranous and cytoplasmic fractions uniquely suitable for chemical and enzymatic characterization. With the large-diameter Gelman filters now available, quantities of erythrocyte membranes sufficient for analysis could be dislodged from the filters by the technique described. 


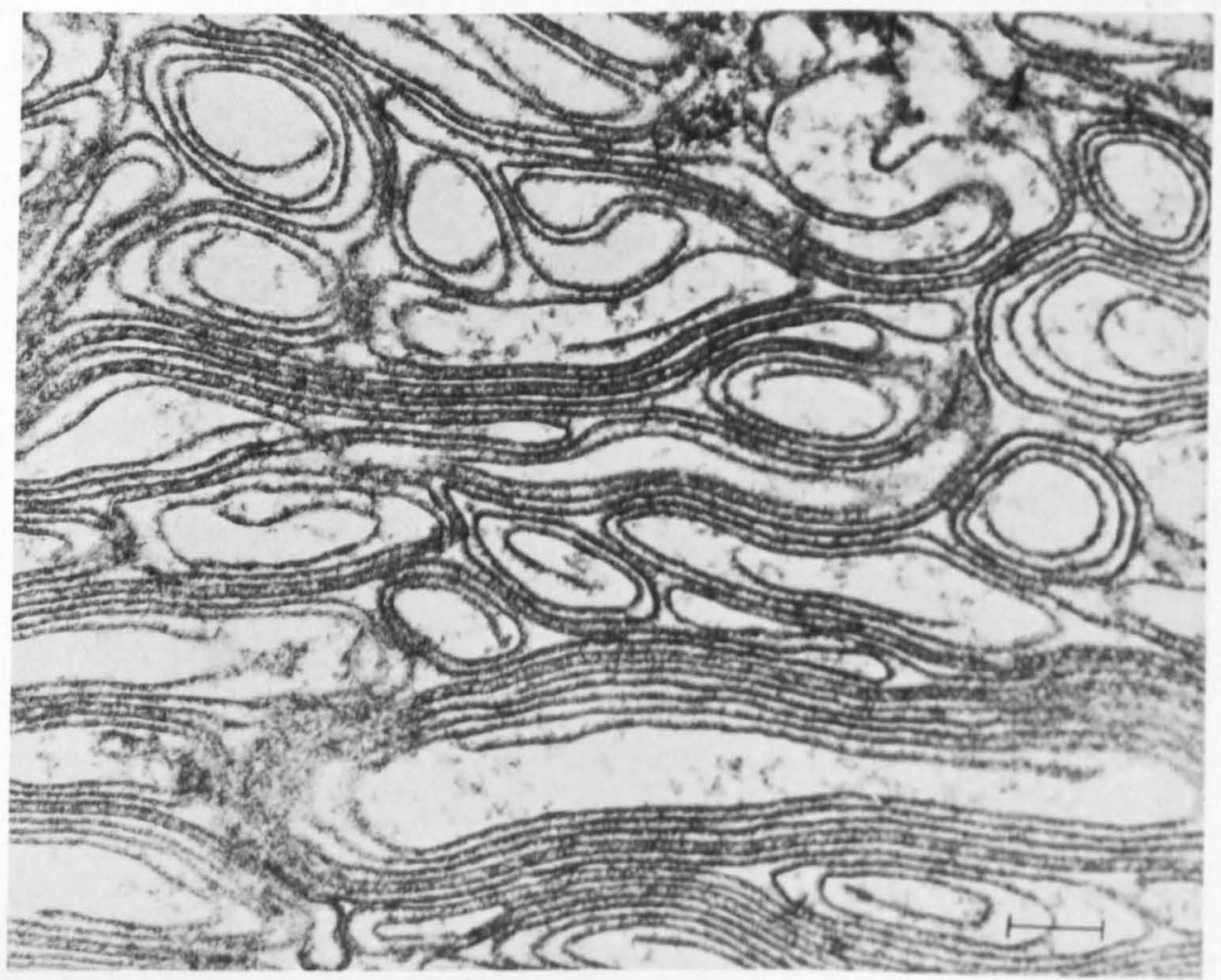

Fig. 5. Electron micrograph of erythrocy te ghosts isolated by centrifugation. Outdated human ery* throcytes were suspended in $0.25 \mathrm{M}$ sucrose and lysed by subjecting the suspension to 25 strokes in a Dounce homogenizer. The ghosts were concentrated by filtration of the suspension on a GA-3 (1.2 $\mu$ mps) filter and were subsequently sedimented by centrifugation at $13,000 \mathrm{~g}$ for 10 minutes. The pellet was fixed, stained, and observed as described in the text (final magnification, $\times 10,000$ ).

The red cell ghosts prepared by this method are free of the more obvious artifacts introduced by centrifugation and thus are well suited for ultrastructural analysis and other physical studies. The filter facilitates preparation for electron microscopy by providing a support for the sample up to the dehydration step. The solubilization of the filter during the dehydration is advantageous in that it eliminates the possibility of ascribing properties of the filter to the sample. The filtration method is thus a gentle lytic procedure that provides an opportunity to obtain erythrocyte ghosts with minimal contamination and structural artifacts.

\section{ACKNOWLEDGMENTS}

The writers gratefully acknowledge the skillful assistance of Mrs. Roberta K. Brabec in the preparation of samples and in photographic work and the efforts of Mr. Douglas Zusman in the initial phase of this work.

This research was supported in part by grants AM09250, ES00339, and GRS Project 112 from the U.S. Public Health Service and by grant FRF-108 from the University of Michigan. 


\section{REFERENCES}

1. Beams IIW, Kessel RG: Electron microscope and ultracentrifugation studies on the rat reticulocyte. Am J Anat 118:471-507, 1966.

2. Beams IWW, Kessel RG: The effects of ultrafiltration on the mammalian erythrocyte. Anat Rec 115: 541-550, 1966.

3. Baudhuin $P$, Evrard P, Berthet J: Electron mictoscopic examination of subcellular fraction. I. The preparation of representative sumples from suspensions of particles. J Cell Biol 32:181-191, 1967.

4. Jandl JII, Simmons RL, Castle WB: Red cell filtration and the pathogenesis of certain hemolytic anemias. Blood 18:133-148, 1961.

5. Prothero JW. Burton AC: The physics of blood flow in capillaries. III. The pressure requirod so deform erythrocytes in acid citrate-dextrose. Biophys J 2:213-222, 1962.

6. Gregersen ML. Bryant CA, Mannerle WE, Usami S, Chien S: Flow characteristics of human exythrocyles through polycarbonate sieves. Science 157:825-827, 1967.

7. Reynaud AJ, King F:B: A new filter for diagnostic cytology. Acta Cytol 11:289-294, 1967.

8. Weed RI, LaCelle PL, Merrill EW: Metabolic dependence of red cell deformability. J Clin Invest 48:795-809. 1969.

9. Card RT. Weintraub LR: Metabolic abnormalities of erythrocytes in severe iron deficiency. Blood $37: 727-732,1971$.

10. Frasca JM. Parks VR: A routine technique for double-staining ultrathin sections using uranyl and lead salts. I Cell Biol 25:157-161, 1965.

11. Reynolds F.S: The use of lead citrate at high pll as an electron-opayue stain in clectron microscopy. J Cell Biol 17:208-215, 1963. 